Original Article

\title{
ISOLATION AND CHARACTERISATION OF RAPAMYCIN, TEMSIROLIMUS REGIO ISOMER (MONOESTER) AND TEMSIROLIMUS DIESTER IN TEMSIROLIMUS DRUG
}

\author{
GORLA S. REDDY, CHAVA V. N. RAO* \\ NRI Institute of Technology, Pothavarappadu, Agiripalli Mandal, Krishna District, A. P., India, 521212 \\ Email: chavavnrao@gmail.com
}

Received: 06 Oct 2018 Revised and Accepted: 05 Jan 2019

\begin{abstract}
Objective: Separation and identification of the process impurities in the manufacture of temsirolimus drug viz., rapamycin, temsirolimus regioisomer (monoester) (TS monoester), and temsirolimus diester (TS diester).

Methods: During the process development of temsirolimus (TS), three process impurities-rapamycin, temsirolimus regioisomer (monoester) and temsirolimus diester-were detected by high-performance liquid chromatography (HPLC). Impurities were isolated by medium pressure liquid Chromatography (MPLC) and characterized by ESI-MS/MS, ${ }^{1} \mathrm{H}$ NMR, FT-IR spectral data.

Results: These impurities are characterised with the help of ESI MS/MS, ${ }^{1} \mathrm{H}$ NMR, and FT-IR data. The impurities are identified and characterised as the process impurities. One of them is the starting material i.e. rapamycin and the other two are formed during the manufacture of the drug. This method offers advantages over using photodiode-array UV detection (LC-PDA) for the determination of peak purity, viz. components with similar
\end{abstract} UV spectra can be distinguished.

Conclusion: The structures of these impurities were characterized as rapamycin, TS Monoester, and TS Diester. Out of these process impurities, rapamycin has been previously identified while the other two are previously unreported.

Keywords: Temsirolimus, Rapamycin, Temsirolimus regioisomer (monoester), Temsirolimus diester, Process impurities, Characterisation

(C) 2019 The Authors. Published by Innovare Academic Sciences Pvt Ltd. This is an open-access article under the CC BY license (http://creativecommons.org/licenses/by/4.0/) DOI: http://dx.doi.org/10.22159/ijpps.2019v11i2.30169

\section{INTRODUCTION}

The most common malignancy of the kidney and accounts for $2 \%$ $3 \%$ of all adult cancers is renal cell carcinoma (RCC) [1]. Though surgical resection can be curative in localized disease, prognosis of advanced renal cell carcinoma is poor with a 5-years survival rate of $5 \%-10 \%$. Immunotherapy with interferon- $\alpha$ (IFN) has produced modest survival benefice in clinical trials [2-7] but high dose interleukin-2, though active in highly selected patients, is associated with toxicity [8, 9]. Since 2007 Phase III studies have emphasized the importance of targeting angiogenesis through vascular endothelial growth factor receptor (VEGFR) tyrosine kinase inhibition with sunitinib [10] and sorafenib [11] or direct VEGF inhibition with bevacizumab in combination with IFN $[12,13]$. The mammalian target of rapamycin (mTOR), a member of the phosphatidylinositol 3 kinase family, is a multifunctional serine-threonine kinase that acts as a central regulator of cell growth, proliferation, and apoptosis [14, 15]. It modulates the expression and stability of hypoxia-inducible factor (HIF)- $1 \alpha$, which regulates expression of VEGF. Temsirolimus (cci-779) is a potent and selective inhibitor of mTOR. It has demonstrated its efficacy as first-line immunotherapy in poor prognosis metastatic RCC in comparison with IFN [16] Temsirolimus (sirolimus-42-[2,2-bis-(hydroxymethyl)]-propionate) is an ester analog of rapamycin, a natural macrolide antibiotic with antifungal, antitumor, and immunosuppressive activities. Temsirolimus has demonstrated significant inhibition of tumour growth both in vitro and in vivo. Temsirolimus is currently in phase III clinical development for the treatment of renal cancer.

The method development of a drug is very important [17] to the pharmaceutical industry as the development of a method is essential for the discovery, development, and evaluation of medicines in the pharmaceutical formulation. The method development and validation of temsirolimus is carried out by the same authors $[18,19]$.

The present study describes the identification and determination of three impurities rapamycin, temsirolimus regioisomer (monoester) (TS monoester) and temsirolimus diester (TS diester) in crude temsirolimus drug [20-22]. All the impurities were isolated using MPLC, characterized by mass spectral data and NMR, FT-IR as additional evidence. The impurities TS monoester and TS diester with hydroxyl ester moiety in the side chain appear to be novel and previously not reported. Impurities in active pharmaceutical ingredient (API) are highly undesirable and in some cases can prove to be harmful to the patient. The ICHQ7 and ICHQ3A are a guide for API manufacturers, mentions that impurities are to be maintained below the set limits. Thus, it is pertinent to identify and characterize the impurities in API to develop suitable process wherein their levels can be kept within permissible limits. The impurity profile study should be carried out for any bulk drug to identify and characterize all the unknown impurities that are present at a level of above $0.1 \%$. A comprehensive study has been undertaken to isolate and characterize these impurities by chromatographic, mass spectral studies and NMR spectroscopic techniques. This article describes the separation, identification, isolation, and characterization of three process impurities that are present in the range of $0.08 \%-0.12 \%$ of peak area of the bulk drug of temsirolimus. The monitoring of these impurities is important for pharmaceutical drug development and quality control of drug substance.

Molecular formula of temsirolimus is $\mathrm{C}_{56} \mathrm{H}_{87} \mathrm{NO}_{16}$ and molar mass is 1030.28. Systematic (IUPAC) name is $(1 \mathrm{R}, 2 \mathrm{R}, 4 \mathrm{~S})-4-\{(2 \mathrm{R})-2$ (3S,6R,7E,9R,10R,12R,14S,15E,17E,19E,21S,23S,26R,27R,34aS)-9,27dihydr-oxy-10,21-dimethoxy-6,8,12,14,20,26-hexamethyl-1,5,11,28,29pentaoxo-1,4,5,6,9,10,11,12,13,14,21,22, 23,24, 25,26,27,28,29,31, 32,33, 34,34a-tetracosa-hydro-3H-23,27-epoxypyrido[2,1-c][1,4] oxazacyclohentri-acontin-3-yl] propyl\}-2-methoxy cyclohexyl 3-hydroxy-2(hydroxymethyl)-2-methyl propanoate. The molecular structure of temsirolimus is given in table 1 .

\section{MATERIALS AND METHODS}

\section{Reagents and chemicals}

The water used in preparing the solutions had been purified by a Milli-Q system (Millipore). n-hexane (HPLC grade), methanol (HPLC 
grade) and acetonitrile (HPLC grade) were purchased from Rankem (Ranbaxy India). Trifluoro acetic acid (HPLC grade), acetic acid (HPLC grade), ethanol (HPLC grade) and ammonia (HPLC grade) were purchased from Sigma-Aldrich (Sigma-Aldrich Ltd). Crude temsirolimus drug sample was obtained from Hetero Drugs Limited Hyderabad, India as gift samples.

\section{High-performance liquid chromatography (analytical)}

A Waters HPLC system equipped with Alliances 2695 series low pressure quaternary gradient pump along with photodiode array detector and autosampler has been used for the analysis of samples. The data was collected and processed using Waters Empower 3 software. The YMC PACK SIL (250 X $4.6 \mathrm{~mm}, 5 \mu \mathrm{m}$, YMC, America, Inc) column was employed for the separation of impurities from temsirolimus. The column eluent was monitored at $280 \mathrm{~nm}$. A simple isocratic Normal-Phase HPLC method was optimized for the separation of impurities from temsirolimus active pharmaceutical ingredient where the mobile phase ratio was a mixture of n-hexane, ethanol and trifluoroacetic acid in a ratio of 90:10:0.01, v/v. Chromatography was performed at column oven temperature $35^{\circ} \mathrm{C}$ with a flow rate of $1.5 \mathrm{ml} \mathrm{min}^{-1}$, auto-sampler temperature $5^{\circ} \mathrm{C}$ and injection volume $10 \mu \mathrm{l}$. The chromatographic run time was $60 \mathrm{~min}$.

\section{Mass spectrometry (LC-MS/MS)}

The LC-MS analysis was carried out on AB Sciex Instruments 4000 Q TRP Linear Ion Trap Quadrupole LC/MS/MS Mass Spectrometer connected with a Waters HPLC system equipped with Alliances 2695 series with PDA detector. The YMC PACK SIL ( 250 X $4.6 \mathrm{~mm}, 5 \mu \mathrm{m}$, YMC, America, Inc) column was used for the separation. A simple isocratic reverse-phase HPLC method was optimized for the separation of impurities from temsirolimus active pharmaceutical ingredient where the mobile phase ratio was a mixture of water, methanol, acetonitrile, and trifluoroacetic acid in a ratio of 15:70:15:0.01, v/v. Chromatography was performed at column oven temperature $35 \mathrm{C}$ at a flow rate of $1.5 \mathrm{~m} \mathrm{l} \mathrm{min}^{-1}$, auto-sampler temperature $5{ }^{\circ} \mathrm{C}$ and injection volume $10 \mu$. The chromatographic run time was $60 \mathrm{~min}$. After chromatographic separation, the mobile phase was directly introduced into the mass spectrometer via electrospray ionization (ESI) source operating in the positive and negative mode. Identification was performed using Q1 MS (Q1) and production (MS2) scan types to optimize all the mass parameters. The curtain gas reached 20 psi. The ion spray voltage was set at $4500 \mathrm{~V}$ and temperature at $475{ }^{\circ} \mathrm{C}$. The nebulizer gas (GS1) and turbo gas (GS2) were 45 and 55 psi. The declustering potential (DP) and entrance potential (EP) were 25 and $10 \mathrm{~V}$. Data acquisition was carried out by analyst 1.4 .2 software on a dell computer.

\section{Isolation of impurities by MPLC}

Crude temsirolimus was dissolved in n-hexane and adsorbed over silica gel (mesh 230-400). This adsorbed compound was applied to MPLC (Buchi R688, column: $70 \mathrm{~cm} \times 460 \mathrm{~cm}$, Fraction Collector Buchi 684) using silica gel (mesh 230-400) as adsorbent and eluted with n-hexane-ethanol. The elution solvents were classified as (A) nhexane and (B) ethanol. The impurities were eluted according to the gradient by changing the $\%$ of $(\mathrm{B})$ at the different time, $\mathrm{T}(\mathrm{min}) / \% \mathrm{~B}$ $=0 / 0,15 / 1,20 / 2.0,30 / 2.5,45 / 3.0,90 / 4.0$ at a flow rate of 50 $\mathrm{ml} / \mathrm{min}$. Fractions of $100 \mathrm{ml}$ were collected, and those exhibiting similar TLC profiles combined. The enriched and purified samples of individual impurities were provided by Hetero Drugs.

\section{NMR spectroscopy}

The NMR experiments were performed on Bruker spectrometers operating at $400 \mathrm{MHz}$ in $\mathrm{CDCl}_{3} .{ }^{1} \mathrm{H}$ chemical shift values were reported on the $\delta$ scale in ppm, relative to TMS $(\delta=0.00)$ as an internal standard.

\section{FT-IR spectroscopy}

Samples were measured as neat by using ATR on Bruker FTIR Spectrometer Alpha (Bruker Corporation, Germany) in the range of $600-4000 \mathrm{~cm}^{-1}$ with 20 scans and $2 \mathrm{~cm}^{-1}$ resolution. OPUS software version 6.5.

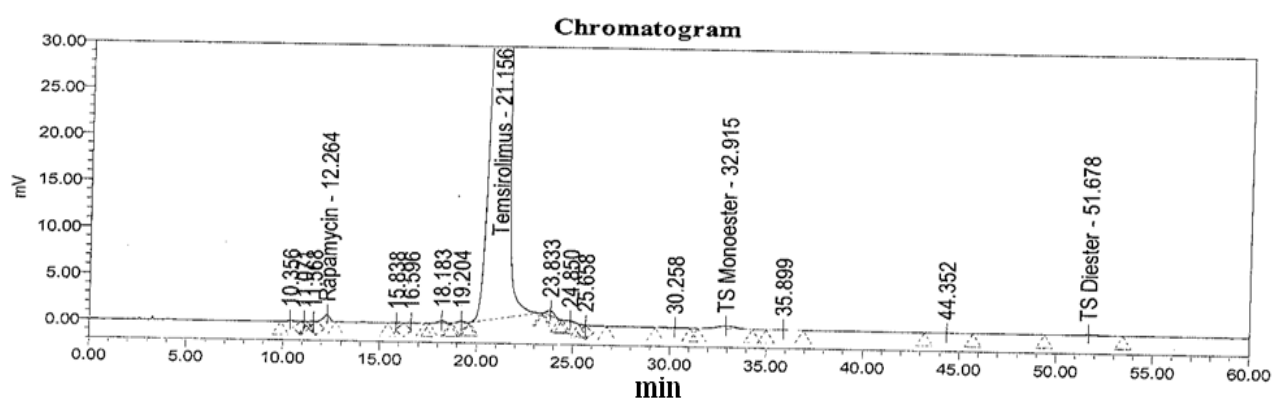

Fig. 1: Crude temsirolimus HPLC chromatogram

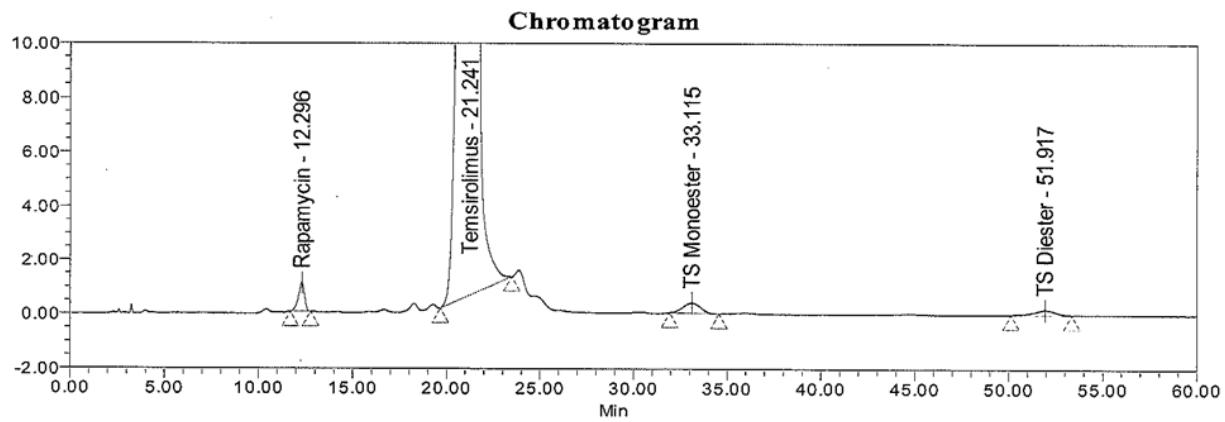

Fig. 2: Temsirolimus impurity spiked HPLC chromatogram

\section{RESULTS AND DISCUSSION}

The HPLC chromatograms of crude temsirolimus and process impurity spiked sample is shown in fig. 1 and 2. The LC/MS data gave the molecular ions of the impurities. HPLC retention time (RT) and the tentative structures deduced from the MS data are shown in table 1. Impurities were isolated using MPLC and characterized by NMR and FTIR spectroscopy. The structures of impurities, 
rapamycin, TS monoester and TS diester were confirmed by the spectral data. The NMR data and IR \& Mass data were compared with those of temsirolimus (table 2, 3).

\section{Structure elucidation of rapamycin}

Rapamycin was formed in temsirolimus drug in the manufacturing process as an impurity and identified as a 31-membered macrocycle of 15 stereo-centers and multiple functional groups, namely transrotamer of 10 -hemiketal. It is a starting material for temsirolimus. The mass spectrum of rapamycin showed an ammonium adduct $\left[\mathrm{M}+\mathrm{NH}_{4}\right]^{+}$at $\mathrm{m} / \mathrm{z}$ 931.5, a protonated molecular ion $[\mathrm{M}+\mathrm{H}]+$ at $\mathrm{m} / \mathrm{z}$ 914.4 and a deprotonated molecular ion $[\mathrm{M}-\mathrm{H}]-$ at $\mathrm{m} / \mathrm{z}$ 912.4, indicating that the rapamycin has a molecular mass less than that of temsirolimus by 116.7 Da. The deprotonated molecular ion [M$\mathrm{H}]^{+}(\mathrm{m} / \mathrm{z}$ 912.4) gave $\mathrm{m} / \mathrm{z}$ at 590, 437 and $261 \mathrm{Da}$ on further fragmentation $[23,24]$. These ions formation agree with the fragmentation pathway of the proposed structure of rapamycin. Further confirmation came from HPLC retention time, FT-IR (table 3 ) and the ${ }^{1} \mathrm{H}$ NMR spectrum (table 2 ) and comparing rapamycin with temsirolimus standard substance. IR spectrum displayed characteristic absorption at 3414.3, 1719.1 and $1644.8 \mathrm{~cm}^{-1}$ corresponding to broad peak $\mathrm{OH}$, non-conjugated $\mathrm{C}=\mathrm{O}$ and conjugated and non-conjugated $\mathrm{C}=\mathrm{C}$ stretching confirming all the major functional groups in rapamycin. In the ${ }^{1} \mathrm{HNMR}$ spectrum of rapamycin, the chemical shift values of ester side chain signals were found to be absent. The ${ }^{1}$ HNMR spectrum of rapamycin (table 2) showed a significant change in the chemical shifts value of the proton in the $\mathrm{C} 60$ position. The $\mathrm{C} 60$ methyl proton signal was found to be absent in rapamycin while in temsirolimus, the C60 methyl proton signal is observed at $1.09 \mathrm{ppm}$. Another significant difference is observed in the ${ }^{1} \mathrm{H}$ NMR spectrum at the C58 and C59 position. C58 and C59 hydroxyl proton signal was found to be absent in rapamycin while in temsirolimus, the C58andC59 hydroxyl proton signal is observed at 2.91-3.01 ppm. The ${ }^{1} \mathrm{HNMR}$ spectrum of rapamycin (table 2) showed a significant change in the chemical shifts value of the proton at the C42 position. The C42 hydroxyl proton signal was found to be present in rapamycin while absent in temsirolimus and hydroxyl proton signal is observed at $3.59 \mathrm{ppm} .{ }^{1} \mathrm{H}$ NMR spectrum of rapamycin confirms the positions of hydrogen atoms and their environment in the molecule. Based on spectral data, rapamycin was confirmed as a single isomeric form, namely trans-rotamer of 10 -hemiketal. The molecular formula of rapamycin is $\mathrm{C}_{51} \mathrm{H}_{79} \mathrm{NO}_{13}$ and molar mass is 913.43 . Systematic (IUPAC) name is $(1 \mathrm{R}, 9 \mathrm{~S}, 12 \mathrm{~S}, 15 \mathrm{R}, 16 \mathrm{E}, 18 \mathrm{R}, 19 \mathrm{R}, 21 \mathrm{R}, 23 \mathrm{~S}, 24 \mathrm{E}, 26 \mathrm{E}, 28 \mathrm{E}, 30 \mathrm{~S}, 32 \mathrm{~S}$, $35 R)-1, \quad 18$-Dihydroxy-12 \{(1R)-2-[(1S, 3R, 4R)-4-hydroxy-3methoxycyclohexyl]-1-methylethyl $\}-19,30$-dimethoxy-15, 17, 21, 23, 29, 35-hexamethyl-11, 36-dioxa-4-azatricyclo [30.3.1.04, 9] hexatriaconta16, 24, 26, 28-tetraen 2,3,10,14,20 penton.

Table 1: Name of the compound, retention time (RT), structure and molecular weight of the impurities

\begin{tabular}{|c|c|c|c|}
\hline Name & RT(HPLC) (min) & Structure & $\mathbf{m} / \mathbf{z}$ \\
\hline Rapamycin & 12.29 & & 913 \\
\hline Temsirolimus & 21.24 & & 1030 \\
\hline TS Regio isomer (Monoester) & 33.11 & & 1030 \\
\hline TS Diester & 51.91 & & 1146 \\
\hline
\end{tabular}


Table 2: ${ }^{1} \mathrm{H}$ NMR data of temsirolimus and temsirolimus process impurities

\begin{tabular}{|c|c|c|c|c|c|c|c|}
\hline \multicolumn{2}{|c|}{ Temsirolimus } & \multicolumn{2}{|c|}{ Rapamycin } & \multicolumn{2}{|c|}{ Ts Monoester } & \multicolumn{2}{|l|}{ Ts diester } \\
\hline$\delta(p p m)$ & Position of proton & $\delta$ (ppm) & Position of proton & $\delta(p p m)$ & Position of proton & $\delta(p p m)$ & Position of proton \\
\hline $0.88-0.90$ & 47 & 0.92 & 47 & 0.92 & 47 & 0.92 & 47 \\
\hline $0.92-0.94$ & 46 & 0.95 & 46 & 0.95 & 46 & 0.95 & 46 \\
\hline $0.96-0.98$ & 51 & 0.99 & 51 & 0.99 & 51 & 0.99 & 51 \\
\hline $1.02-1.04$ & 49 & 1.05 & 49 & 1.05 & 49 & 1.05 & 49 \\
\hline $1.07-1.08$ & 50 & 1.08 & 50 & 1.08 & 50 & 1.08 & 50 \\
\hline 1.09 & 60 & - & - & 1.12 & 60 & 1.23 & 60,65 \\
\hline $1.12-1.26$ & $19,20,21$ & $1.2-1.3$ & $19,20,21$ & $1.2-1.3$ & $19,20,21$ & $1.2-1.3$ & $19,20,21$ \\
\hline $1.45-1.46$ & $43,10,11$ & $1.4-1.54$ & $43,11,10$ & $1.4-1.54$ & $43,11,10$ & $1.4-1.54$ & $43,11,10$ \\
\hline $1.57-1.60$ & 35,48 & $1.58-1.65$ & 35,48 & $1.58-1.65$ & 35,48 & $1.58-1.65$ & 35,48 \\
\hline 1.63 & 44,38 & $1.60-1.87$ & 44,38 & $1.60-1.87$ & 44,38 & $1.60-1.87$ & 44,38 \\
\hline 1.73 & 45 & 1.76 & 45 & 1.76 & 45 & 1.76 & 45 \\
\hline $2.03-2.06$ & $26,8,12$ & $1.95-2.09$ & 8,12 & $1.95-2.09$ & 8,12 & $1.95-2.09$ & 8,12 \\
\hline $2.13-2.15$ & $31-\mathrm{OH}$ & $2.81-2.89$ & $31-\mathrm{OH}$ & - & - & - & - \\
\hline $2.30-2.34$ & 34,36 & $2.10-2.59$ & $26,34,36$ & $2.10-2.59$ & $26,34,36$ & $2.10-2.59$ & $26,34,36$ \\
\hline $2.58-2.59$ & 39,37 & $2.39,2.70$ & 37,39 & $2.39,2.70$ & 37,39 & $2.39,2.70$ & 37,39 \\
\hline $2.67-2.73$ & 40 & 2.79 & 40 & 2.79 & 40 & 2.79 & 40 \\
\hline $2.91-3.01$ & $58,59-\mathrm{OH}$ & - & - & $2.91-3.05$ & $58,59-\mathrm{OH}$ & $2.91-3.05$ & $63,64,58,59-\mathrm{OH}$ \\
\hline 3.12 & 53 & 3.14 & 53 & 3.14 & 53 & 3.14 & 53 \\
\hline $3.28-3.37$ & $39,28,18$ & $3.17-3.47$ & 18,28 & $3.17-3.47$ & 18,28 & $3.17-3.47$ & 18,28 \\
\hline 3.31 & 54 & 3.33 & 54 & 3.33 & 54 & 3.33 & 54 \\
\hline 3.34 & 52 & 3.35 & 52 & 3.35 & 52 & 3.35 & 52 \\
\hline- & - & 3.59 & $55-\mathrm{OH}$ & 3.93 & $55-\mathrm{OH}$ & - & - \\
\hline $3.57-3.85$ & $58,59,41,32,7,9$ & $3.55-3.88$ & $41,7,32,9$ & $3.55-3.88$ & $58,59,41,7,32,9$ & $3.55-3.88$ & $63,64,58,59,41,7,3,2,9$ \\
\hline $4.16-4.19$ & 25 & 4.18 & 25 & 4.18 & 25 & 4.18 & 25 \\
\hline $4.68-4.74$ & 42 & 4.71 & 42 & 4.71 & 42 & 4.71 & 42 \\
\hline 4.78 & $13-\mathrm{OH}$ & 4.78 & $13-\mathrm{OH}$ & 4.78 & $13-\mathrm{OH}$ & 4.78 & $13-\mathrm{OH}$ \\
\hline $5.14-5.17$ & 22 & 5.11 & 22 & 5.11 & 22 & 5.11 & 22 \\
\hline 5.38-5.41 & 31 & 5.27 & 31 & 5.27 & 31 & 5.27 & 31 \\
\hline $5.46-5.55$ & 29,1 & $5.40-5.56$ & 29,1 & $5.40-5.56$ & 29,1 & $5.40-5.56$ & 29,1 \\
\hline $5.93-5.96$ & 5 & $5.69-5.99$ & 5 & $5.69-5.99$ & 5 & $5.69-5.99$ & 5 \\
\hline $6.09-6.15$ & 2 & $6.11-6.13$ & 2 & $6.11-6.13$ & 2 & $6.11-6.13$ & 2 \\
\hline $6.18-6.40$ & 3,4 & $6.29-6.39$ & 3,4 & $6.29-6.39$ & 3,4 & $6.29-6.39$ & 3,4 \\
\hline
\end{tabular}

Table 3: FT-IR and mass spectral data of temsirolimus and impurities (rapamycin, TS monoester and TS diester)

\begin{tabular}{|c|c|c|c|}
\hline S. No. & Compound & IR & MS \\
\hline 1 & Rapamycin & $\begin{array}{l}\text { 3414(OH stretching), 2966(aliphatic C-H stretching), } 1719(\mathrm{C}=0 \\
\text { stretching), } 1644(\mathrm{C}=\mathrm{C} \text { aromatic stretching), } 1449(\mathrm{~N}-\mathrm{H} \text { bending), } \\
\text { 1383(aliphatic C-H stretching), 1280, 1103(C-O stretching), 1199(C-N } \\
\text { stretching) and } 756 \text { (aromatic C-H bending). }\end{array}$ & $\begin{array}{l}\text { +ve ES-MS: } 914(\mathrm{M}+\mathrm{H})^{+}, 931\left(\mathrm{M}+\mathrm{NH}_{4}\right)^{+} \\
936(\mathrm{M}+\mathrm{Na})^{+}, 952(\mathrm{M}+\mathrm{K})^{+} ;- \text {-ve ES-MS: } 912 \\
(\mathrm{M}-\mathrm{H})^{-}, 947(\mathrm{M}+\mathrm{Cl})^{-}\end{array}$ \\
\hline 2 & TS monoester & $\begin{array}{l}\text { 3376(OH stretching), 2961(aliphatic C-H stretching), } 1718(\mathrm{C}=0 \\
\text { stretching), } 1641(\mathrm{C}=\mathrm{C} \text { aromatic stretching), } 1459(\mathrm{~N}-\mathrm{H} \text { bending), } \\
\text { 1378(aliphatic C-H stretching), 1262, 1101(C-O stretching), 1198(C-N } \\
\text { stretching) and } 809 \text { (aromatic C-H bending). }\end{array}$ & $\begin{array}{l}\text { +ve ES-MS: } 1031(\mathrm{M}+\mathrm{H})+, 1048 \\
\left(\mathrm{M}+\mathrm{NH}_{4}\right)^{+}, 1053(\mathrm{M}+\mathrm{Na})^{+}, 1069(\mathrm{M}+\mathrm{K})^{+;} ; \\
\text {ve ES-MS: } 1029(\mathrm{M}-\mathrm{H})^{-}, 1064(\mathrm{M}+\mathrm{Cl})^{-}\end{array}$ \\
\hline 3 & TS diester & $\begin{array}{l}\text { 3456(OH stretching), 2935(aliphatic C-H stretching), } 1726(\mathrm{C}=0 \\
\text { stretching), } 1640(\mathrm{C}=\mathrm{C} \text { aromatic stretching), } 1456(\mathrm{~N}-\mathrm{H} \text { bending), } \\
\text { 1392(aliphatic C-H stretching), 1291, 1108(C-O stretching), 1198(C-N }\end{array}$ & $\begin{array}{l}\text { +ve ES-MS: } 1148(\mathrm{M}+\mathrm{H})+, 1165 \\
\left(\mathrm{M}+\mathrm{NH}_{4}\right)^{+}, 1170(\mathrm{M}+\mathrm{Na})^{+}, 1186(\mathrm{M}+\mathrm{K})^{+} \\
\text {-ve ES-MS: } 1146(\mathrm{M})^{-}, 1145(\mathrm{M}-\mathrm{H})^{-} \\
1181(\mathrm{M}+\mathrm{Cl})\end{array}$ \\
\hline 4 & Temsirolimus & $\begin{array}{l}\text { 3454(OH stretching), 2965(aliphatic C-H stretching), } 1721(\mathrm{C}=\mathrm{O} \\
\text { stretching), } 1644(\mathrm{C}=\mathrm{C} \text { aromatic stretching), } 1453(\mathrm{~N}-\mathrm{H} \text { bending), } \\
1392 \text { (aliphatic C-H stretching), 1288, 1103(C-O stretching), 1193(C-N } \\
\text { stretching) and } 740 \text { (aromatic C-H bending). }\end{array}$ & $\begin{array}{l}\text { +ve ES-MS: } 1031(\mathrm{M}+\mathrm{H})^{+}, 1048\left(\mathrm{M}+\mathrm{NH}_{4}\right)^{+}, \\
\text {1053(M+Na)+, } 1069(\mathrm{M}+\mathrm{K})^{+} ;- \text {-ve ES-MS: } \\
1029(\mathrm{M}-\mathrm{H})^{-}, 1064(\mathrm{M}+\mathrm{Cl})^{-} \text {. }\end{array}$ \\
\hline
\end{tabular}

\section{Structure elucidation of TS monoester}

This impurity TS Monoester was formed in temsirolimus drug during the manufacturing process and identified as 31-membered macrocycle of 15 stereo-centers and multiple functional groups, namely temsirolimus regioisomer. This is a hydroxyl ester at the 31 positions of rapamycin. The ESI mass spectrum of TS monoester showed an ammonium adduct $\left[\mathrm{M}+\mathrm{NH}_{4}\right]+$ at $\mathrm{m} / \mathrm{z} 1047.6$ and sodium adduct $[\mathrm{M}+\mathrm{Na}]+$ at $\mathrm{m} / \mathrm{z}$ 1052.6, a protonated molecular ion $[\mathrm{M}+\mathrm{H}]+\mathrm{at}$ $\mathrm{m} / \mathrm{z} 1031.4$ and a deprotonated molecular ion $[\mathrm{M}-\mathrm{H}]+\mathrm{at} \mathrm{m} / \mathrm{z}$ 1029.37, which is like temsirolimus. TS monoester gave two fragment ions at m/z 590 (A) and m/z 437 (B) in the MS/MS experiment $[23,24]$. These two ions resulted from the cleavage of the $\mathrm{C} 31 / \mathrm{C} 32$ bond and the $024 / \mathrm{C} 25$ ester bond. These characteristic cleavages are also observed in rapamycin and temsirolimus with the loss of neutral species, such as $\mathrm{H}_{2} \mathrm{O}, \mathrm{MeOH}$, and/or $\mathrm{CO}_{2}$. B ion further generated the fragment ions of $\mathrm{m} / \mathrm{z} 407, \mathrm{~m} / \mathrm{z} 389$ and $\mathrm{m} / \mathrm{z} 371$ and ion A produced the fragment ions of $\mathrm{m} / \mathrm{z} 546, \mathrm{~m} / \mathrm{z} 528, \mathrm{~m} / \mathrm{z} 514$, and $\mathrm{m} / \mathrm{z}$ 496. Further cleavage of $\mathrm{A}$ ion at C8/C9 and C35/C36 (allylic cleavage) followed by loss of methanol gave fragment ions at $\mathrm{m} / \mathrm{z} 261, \mathrm{~m} / \mathrm{z} 229$ and m/z 147. $\beta$-Cleavage of C33 ketone produced the fragment ion of $\mathrm{m} / \mathrm{z} 101[23,24]$. The ion at $\mathrm{m} / \mathrm{z} 252$ was formed by $\mathrm{C} 8 / \mathrm{C} 9$ cleavage followed by $\mathrm{CO}_{2}$ loss (cleavage at $\mathrm{C} 22 / \mathrm{C} 23$ ) in the left region of the $\mathrm{A}$ ion. The ion $\mathrm{m} / \mathrm{z} 234$ resulted from a further loss of $\mathrm{H}_{2} \mathrm{O}$. Additional fragment ions at m/z 168 and $\mathrm{m} / \mathrm{z} 128$ arose from cleavages occurring at C13/C15 and C23/024 and cleavage of the amide bond (C16/N17) respectively. These ions $(\mathrm{m} / \mathrm{z} 252, \mathrm{~m} / \mathrm{z} 234, \mathrm{~m} / \mathrm{z} 168$, and $\mathrm{m} / \mathrm{z}$ 128) from the left region of the $\mathrm{A}$ ion. This fragmentation pattern is also found to be same as temsirolimus fragmentation $[23,24]$. A significant difference is 
observed in the ${ }^{1} \mathrm{H}$ NMR spectrum (table 2) and HPLC retention time of TS monoester with respect to temsirolimus. This shows that the TS monoester could be an isomer of temsirolimus. These fragment ions agree with the fragmentation pathway of the proposed structure of TS monoester. Further confirmation came from HPLC retention time, FT-IR spectrum (table 3 ) and ${ }^{1} \mathrm{H}$ NMR spectrum (table 2) and comparing TS monoester with temsirolimus standard substance spectral data. IR spectrum displayed characteristic absorption at $3375.9,1718.5$ and $1641.42 \mathrm{~cm}^{-1}$ corresponding to broad peak $\mathrm{OH}$, non-conjugated $\mathrm{C}=\mathrm{O}$ and conjugated and nonconjugated $\mathrm{C}=\mathrm{C}$ stretching. Therefore, infrared spectrum of the compound confirms all the major functional groups presented in the TS monoester. ${ }^{1} \mathrm{H}$ NMR spectrum of TS monoester (table 2) showed a significant change in the chemical shift value of the proton at the C31 position. C31 hydroxyl proton signal was found to be absent in TS Monoester while in temsirolimus, the C31 hydroxyl proton signal is observed at 2.13-2.15 ppm. Another significant difference is observed in the chemical shift value of the proton at the C42 position. The C42 hydroxyl proton signal was found to be present in TS monoester while absent in temsirolimus, the C42 hydroxyl proton signal is observed at $3.93 \mathrm{ppm} .{ }^{1} \mathrm{HNMR}$ spectrum of TS monoester confirms the positions of hydrogen atoms and their environment in the molecule. Based on spectral data, TS monoester is confirmed as regio isomeric form of temsirolimus. Molecular formula of TS monoester is $\mathrm{C}_{56} \mathrm{H}_{87} \mathrm{NO}_{16}$ and molar mass is 1030.29 . Systematic (IUPAC) name is (3S, 6R, 7E, 9R, 10R, 12R, 14S, 15E, 17E, 19E, 21S, 23S, 26R, 27R, 34aS)-27-hydroxy-3\{(2R)-1-[(1S, 3R, 4R)-4hydroxy-3-methoxycyclohexyl]propan-2-yl\}-10, 21-dimethoxy 6, 8, 12, 14, 20, 26-hexamethyl-1,5,11,28,29-pentaoxo 1, 4, 5, 6, 9, 10, 11, $12,13,14,21,22,23,24,25,26,27,28,29,31,32,33,34,34$ atetracosahydro-3H-23,27-epoxypyrido-[2,1-c][1,4] oxazacyclo-hentriacontin-9-yl-3-hydroxy-2-(hydroxymethyl)-2-methyl propanoate.

\section{Structure elucidation of TS diester}

TS diester is yet another impurity formed during the manufacture of temsirolimus drug and it is identified as 31-membered macrocycle of 15 stereo-centers and multiple functional groups with a hydroxyl ester process impurity for temsirolimus for the 31 position. The mass spectrum of TS diester showed an ammonium adduct $\left[\mathrm{M}+\mathrm{NH}_{4}\right]+\mathrm{m} / \mathrm{z}$ 1164.7, a protonated molecular ion $[\mathrm{M}+\mathrm{H}]+\mathrm{m} / \mathrm{z}$ 1148.1 and a deprotonated molecular ion [M-H]-at m/z 1145.5 in ES negative mode, indicating that the TS Diester has molecular mass more than that of temsirolimus by $116.5 \mathrm{Da}$. Hence the TS diester is an ester of temsirolimus. TS diester exhibited a molecular ion at $\mathrm{m} / \mathrm{z}$ 1146.5 in the negative ESI MS spectrum. TS diester on fragmentation gave two important ions at m/z 590 (A) and m/z 437 (B) in the MS/MS experiment. These characteristic cleavages were also observed in rapamycin, TS monoester and temsirolimus with the loss of neutral species, such as $\mathrm{H}_{2} \mathrm{O}, \mathrm{MeOH}$, and/or $\mathrm{CO}_{2}$ [23,24]. B ion on fragmentation generated ions of $\mathrm{m} / \mathrm{z} 407, \mathrm{~m} / \mathrm{z} 389$, and $\mathrm{m} / \mathrm{z}$ 371 . The A ion produced fragment ions of $\mathrm{m} / \mathrm{z} 546, \mathrm{~m} / \mathrm{z} 528, \mathrm{~m} / \mathrm{z}$ 514 , and $\mathrm{m} / \mathrm{z} 496$. This same fragmentation pattern was found in temsirolimus $[23,24]$ also. This indicates that TS diester could be an ester of temsirolimus. A significant difference is observed in the ${ }^{1} \mathrm{H}$ NMR spectrum (table 2) of TS diester with respect to temsirolimus. Further confirmation was given by the HPLC retention time, FT-IR (table 3) and ${ }^{1} \mathrm{H}$ NMR spectrum (table 2) and comparing TS monoester with temsirolimus standard substance. IR spectrum displayed characteristic absorption at 3453.6, 2965.6, 2934.7 1721.0 and $1644.4 \mathrm{~cm}^{-1}$ corresponding to broad peak $\mathrm{O}-\mathrm{H}$ stretching, aliphatic $\mathrm{C}-\mathrm{H}$ stretching, non-conjugated $\mathrm{C}=\mathrm{O}$ and conjugated and non-conjugated $\mathrm{C}=\mathrm{C}$ stretching. These infrared spectral values confirm the major functional groups presented in the TS diester. ${ }^{1} \mathrm{H}$ NMR spectrum of TS monoester (table 2) showed a ${ }^{1} \mathrm{H}$ chemical shifts value of the proton at the C31 position. This C31 hydroxyl proton signal was absent in TS diester. In temsirolimus, the C31 hydroxyl proton signal is observed at 2.13-2.15 ppm. Another significant difference is observed in the ${ }^{1} \mathrm{H}$ chemical shifts value of the proton at the $\mathrm{C} 65$ position. The $\mathrm{C} 65$ methyl proton signal was found to be present in TS diester while absent in temsirolimus. C65 methyl proton signal is observed at $1.23 \mathrm{ppm}$. One more significant difference is observed in the ${ }^{1} \mathrm{H}$ chemical shifts value of the proton at the C63 and C64 position. The C63 andC64 hydroxyl proton signal was found to be present in TS diester which is absent in temsirolimus. C63andC64 hydroxyl protons signal are observed at 2.91-3.05 ppm. Another difference is observed in the chemical shifts value of the proton at the C42 position also. The C42 hydroxyl proton signal is found to be absent in TS diester while in TS monoester the C42 hydroxyl proton signal is observed at $3.93 \mathrm{ppm}$. One another significant difference is observed in the ${ }^{1} \mathrm{H}$ chemical shifts value of the proton at the C63 and C64 position. The C63 andC64 methyl proton signal was found to be present in TS diester while absent in TS. In TS diester C63andC64 methyl proton signal is observed at 3.55-3.88 ppm. ${ }^{1} \mathrm{H}$ NMR spectrum of TS diester confirms the remaining hydrogen atoms and their environment in the molecule. Based on spectral data, TS diester is confirmed as hydroxyl ester of temsirolimus. A molecular formula of TS diester is $\mathrm{C}_{61} \mathrm{H}_{95} \mathrm{NO}_{19}$ and molar mass is 1146.40 . Systematic (IUPAC) name is (1R, 2R, 4S)-4-\{(2R)-2-[(3S, 6R, 7E, 9R, 10R, 12R, 14S, 15E, 17E, 19E, 21S, 23S, 26R, 27R, 34aS)-27-hydroxy-9-\{[3-hydroxy-2(hydroxymethyl)-2-methylpropanoyl] oxy\}-10, 21-dimethoxy-6, 8, 12, 14, 20, 26-hexamethyl-15, 11, 28, 29-pentaoxo-1, 4, 5, 6, 9, 10, $11,12,13,14,21,22,23,24,25,26,27,28,29,31,32,33,34,34 a-$ tetracosahydro-3H-23, 27-epoxypyrido[2, 1-c][1,4] oxazacyclohentriacontin-3-yl]propyl\}-2-methoxycyclohexyl 3-hydroxy-2(hydroxymethyl)-2-methyl propanoate.

\section{CONCLUSION}

Temsirolimus (sirolimus-42-[2,2-bis-(hydroxymethyl)]-propionate) is an ester analog of rapamycin, a natural macrolide antibiotic with antifungal, antitumor, and immunosuppressive activities. The present research work describes a HPLC method for detection, separation of three process related impurities from temsirolimus and MPLC method for isolation of these impurities from the temsirolimus bulk drug. All the three impurities detected, were characterized with the help of LCMS/MS, FT-IR and NMR experimental data but mainly depends on their retention times in chromatography. Of these three process impurities, one impurity rapamycin was previously known, while other two process impurities were found to be novel and were characterized as temsirolimus regioisomer (monoester) and temsirolimus diester in this study.

\section{AUTHORS CONTRIBUTIONS}

Gorla S Reddy contributed much in the collection and analysis of data. He also interpreted the experimental work in our laboratories. Design and critical revision of the work and in the drafting of the article has been done by Chava V N Rao. DR. Chava V N Rao is the supervisor of this present work.

\section{CONFLICT OF INTERESTS}

The authors declare that they have no conflict of interest. This work and this article do not contain any studies with animals or human participants performed by any of the authors.

\section{REFERENCES}

1. Jemal A, Siegel R, Ward E, Hao Y, Xu J, Thun MJ. Cancer statistics. C A Cancer J Clin 2009;59:225-49.

2. Aass A, De Mulder PH, Mickisch GH, Mulders P, van Oosterom AT, van Poppel H, et al. Randomized phase II/III trial of interferon Alfa-2a with and without 13-cis-retinoic acid in patients with progressive metastatic renal cell carcinoma: the european organisation for research and treatment of cancer genito-urinary tract cancer group (EORTC 30951). J Clin Oncol 2005;23:4172-8.

3. Fossa SD, Martinelli G, Otto U, Schneider G, Wander H, Oberling $\mathrm{F}$, et al. Recombinant interferon alfa-2a with or without vinblastine in metastatic renal cell carcinoma: results of a European multi-center phase III study. Ann Oncol 1992;3:301-5.

4. Minasian LM, Motzer RJ, Gluck L, Mazumdar M, Vlamis V, Krown SE. Interferon alfa-2a in advanced renal cell carcinoma: treatment results and survival in 159 patients with long-term follow-up. J Clin Oncol 1993;11:1368-75.

5. Muss HB, Costanzi JJ, Leavitt R, Williams RD, Kempf RA, Pollard $\mathrm{R}$, et al. Recombinant alfa interferon in renal cell carcinoma: $\mathrm{a}$ randomized trial of two routes of administration. J Clin Oncol 1987;5:286-91. 
6. Negrier S, Escudier B, Lasset C, Douillard IY, Savary J, Chevreau C, et al. Recombinant human interleukin-2, recombinant human interferon alfa-2a, or both in metastatic renal-cell carcinoma. Groupe Francais d'Immunotherapie. N Engl J Med 1998;338:1272-8.

7. Otto U, Schneider AW, Conrad S, Klosterhalfen H. Recombinant alpha-2 or gamma interferon in the treatment of metastatic renal cell carcinoma: results of two phase II/III trials. Prog Clin Biol Res 1990;350:275-82.

8. Atkins MB, Sparano J, Fisher RI, Weiss GR, Margolin KA, Fink KI, et al. Randomized phase II trial of high-dose interleukin-2 either alone or in combination with interferon alfa-2b in advanced renal cell carcinoma. J Clin Oncol 1993;1:661-70.

9. McDermott DF, Regan MM, Clark JI, Flaherty LE, Weiss GR, Logan TF, et al. Randomized phase III trial of high-dose interleukin-2 versus subcutaneous interleukin-2 and interferon in patients with metastatic renal cell carcinoma.J Clin Oncol 2005;23:133-41.

10. Motzer RJ, Hutson TE, Tomczak P, Michaelson MD, Bukowski RM, Rixe 0, et al. Sunitinib versus interferon alfa in metastatic renal-cell carcinoma. N Engl J Med 2007;356:115-24.

11. Escudier B, Eisen T, Stadler WM, Szczylik C, Oudard S, Siebels $\mathrm{M}$, et al. Sorafenib in advanced clear-cell renal-cell carcinoma. $\mathrm{N}$ Engl J Med 2007;356:125-34.

12. Rubio Viqueira B, Hidalgo M. Targeting mTOR for cancer treatment. Curr Opin Invest Drugs 2006;7:501-12.

13. Del Bufalo D, Ciuffreda L, Trisciuoglio D, Desideri M, Cognetti F, Zupi G, et al. Antiangiogenic potential of the mammalian target of rapamycin inhibitor temsirolimus. Cancer Res 2006;66:5549-54.

14. Baldo P, Cecco S, Giacomin E, Lazzarini R, Ros B, Marastoni S. mTOR pathway and mTOR inhibitors as agents for cancer therapy. Curr Cancer Drug Targets 2008;8:647-65.

15. Houeiri TK, Je Y, Sonpavde G, Richards CJ, Galsky MD, Nguyen $\mathrm{PL}$, et al. Incidence and risk of treatment-related mortality in cancer patients treated with the mammalian target of rapamycin inhibitors. Ann Oncol 2013;24:2092-7.
16. Thomas GV, Chris Tran, Mellinghoff IK, Welsbie DS, Chan E, Fueger B, et al. Hypoxia-inducible factor determines sensitivity to inhibitors of mTOR in kidney cancer. Nat Med 2006;12:122-7.

17. Shivani Sharma, Swapnil Goyal, Kalindi Chauhan. A review on analytical method development and validation. Int J Appl Pharm 2018;10:8-15.

18. Nageswara Rao CV, Gorla Sanjeeva Reddy. Orthogonal method development and validation of reverse phase ultraperformance liquid chromatographic-mass spectrometry (using PDA and QDa mass detector) for quantification of temsirolimus in temsirolimus pharmaceutical dosage forms. J Pharm Biol Sci 2017;5:278-89.

19. Gorla Sanjeeva Reddy, Chava VN Rao. Separation and quantitation of rapamycin, temsirolimus regio isomer (monoester and temsirolimus diester in temsirolimus by normal phase HPLC. Saudi J Med Pharm Sci 2018;4:1064-74.

20. Ansermot N, Fathi M, Veuthey JL, Desmeules J, Rudaz S, Hochstrasser D. Simultaneous quantification of cyclosporine, tacrolimus, sirolimus and everolimus in whole blood by liquid chromatography-electrospray mass spectrometry. Clin Biochem 2008;41:728-35.

21. Hamideh Sobhania, Alireza Shafaatib, Nastaran Nafissi Varchehc, Reza Aboofazelia. A reversed phase high performance liquid chromatographic method for determination of rapamycin. Iranian $J$ Pharm Res 2013;12(Suppl):77-81.

22. Xianhua Zhang, Alexander Louie, Xiaohua Li, Robert Shi, Robin K Kelley, Yong Huang. A simple and sensitive LC-MS/MS method for simultaneous determination of temsirolimus and its major metabolite in human whole blood. Chromatographia 2012;75:1405-13

23. Ping Cai, Rushung Tsao, Mark E Ruppen. In vitro metabolic study of temsirolimus: preparation, isolation, and identification of the metabolites. Drug Metab Drug Dispos 2007;35:1554-63.

24. Allen F, Greiner R, Wishart D. Competitive fragmentation modelling of ESI-MS/MS spectra for putative metabolite identification. Metabolomics 2015;11:98-110. 